\title{
AsSOCIATION OF THR241MeT POLYMORPHism OF XRCC3 GeNe With Risk of COlorectal CANCER IN THE POLISH POPULATION
}

\author{
Bartosz Mucha ${ }^{1}$, Karolina Przybylowska-Sygut ${ }^{1}$, Adam Janusz Dziki ${ }^{2}$, Lukasz Dziki ${ }^{2}$, \\ AndrZej SyguT ${ }^{2}$, IRENEUSZ MajSTEREK ${ }^{1}$
}

\author{
${ }^{1}$ Department of Clinical Chemistry and Biochemistry, Medical University in Lodz, Poland \\ 2Department of General and Colorectal Surgery, Medical University in Lodz, Poland
}

\begin{abstract}
DNA double strand breaks (DSBs) are the most dangerous lesions which can lead to carcinogenesis. Homologous recombination (HR) is an important pathway responsible for maintaining genome integrity through repair of DSBs. Single nucleotide polymorphism (SNP) is an essential source of genetic variation whose presence in genes involved in HR may have a crucial role in modulation of DNA repair capacity.

This case-control study was designed to evaluate the influence of XRCC3 gene Thr241Met polymorphism on CRC risk and progression among Polish population. Genotyping was performed by RFLP-PCR (restriction length fragment polymorphism). The subject of our study was consist of 194 patients with CRC and 204 cancer-free individuals who were age and sex-matched as a control group.

Obtained genotype distributions in controls as well as patients fit to the HardyWeinberg expectations. Odd ratio analysis indicates diminished risk for heterozygous model and Met allele. Comparison of patients with noninvasive and advanced stage of CRC did not imply any statistical significance.

Our results suggest that Thr241Met XRCC3 gene polymorphism might be regarded as CRC potential molecular marker. Nevertheless, that hypothesis needs to be confirmed by subsequent studies.
\end{abstract}

Key words: colorectal cancer, homologous recombination, XRCC3, DNA double strand breaks.

\section{Introduction}

Colorectal cancer (CRC) is one of the most common causes of morbidity and mortality in highly industrialized countries. Recent epidemiological data point to a steady increase in incidence [1]. European statistical estimations put CRC in second place in terms of occurrence as well as rate of death [2]. Due to the complexity and multi-stage character of the CRC development process, the interaction between genetic and environmental factors is considered essential. That assumption seems to be confirmed by the quantity of sporadic cancer cases, which is about $90 \%$, whereas only $10 \%$ bear the hallmark of hereditariness [3].
Entrance of a cell on the carcinogenesis pathway is strictly associated with loss of genome integrity. Disturbances in genome may act as the trigger for the protooncogenes, silencing of the suppressor genes, then immortalization and loss of contact inhibition by the cell. DNA is permanently exposed to several damaging agents, which results in the appearance of many types of lesions. DNA double strand breaks (DSBs) are perceived as the most dangerous for genome integrity. Moreover, depending on damage location, even one DSB may cause cell death [4]. In order to maintain proper functioning of the genome, cells are equipped with several response mechanisms which ensure repair. Homologous recombination (HR) is one of the crucial pathways of DSB processing, particularly due to fidelity of re-con- 
structing the sequence [5]. The greatest intensity of $\mathrm{HR}$ is observed during $\mathrm{S}$ phase of the cell cycle, when the genome undergoes division, and it is the most vulnerable to damage agents [6]. The course of the HR process is multistage and requires the involvement of a large set of proteins. The RAD 51 gene is usually taken into consideration as a potential risk modulator of many cancers [7]. At the lesion site, RAD51 and its paralogous proteins form the structure of a nucleoprotein filament on single strand DNA ends, then recognize a homologous region and perform the invasion of 3' free ends in order to re-synthesize the lost sequence. XRCC3 (Xray cross-complementing group 3) is a member of the RAD51 family of proteins which participate in $\mathrm{HR}$, being involved in recruitment of RAD51 at the DSB site $[8,9]$. Furthermore, there are several premises indicating a wide range of functions in other stages of $\mathrm{HR}$, such as participating in resolution of Holliday junction structure $[10]$ and modulation of replication fork progression on damaged chromosomes [11].

Genetic variation occurring in the XRCC3 gene may lead to a change in activity of its protein or interaction with other proteins involved in HR [12]. The vast majority of investigations concern the XRCC3 single nucleotide polymorphism (SNP) in exon 7 C18067T which results in substitution of amino acid threonine to methionine at codon 241 (Thr241Met; rs861539). Alteration in the protein sequence could potentially affect the capacity for environmental DNA damage agents response, thereby conditions the propensity of individuals to develop cancer. In terms of cancer risk, Thr241Met has been very extensively studied in several types of malignancies, especially in lung cancer, breast cancer, head and neck cancer, colorectal cancer, bladder cancer and many others. The outcomes of individual studies tend to be inconsistent, indicating negative as well as positive or lack of association of Thr241Met polymorphism, even within the same type of cancer and the same ethnicity. Despite the abundance of reports, the association is still not completely clear. Nevertheless, some meta-analyses attempt to establish the level of influence [13-15].

In the present paper there are described the course and results of our case-control study, carried out in order to assess the impact of Thr241Met polymorphism on risk and progression of CRC in the Polish population.

\section{Material and methods}

The subject of our research comprised 194 peripheral blood samples collected from patients with sporadic CRC. Cases included unrelated men and women, each with a histologically confirmed diagnosis of CRC. The main familial syndromes, such as FAP and Lynch syndrome, were excluded from the research. The histological grades of tumors were determined according to a threedegree scale as follows: 16 grade I, 165 grade II and 13 grade III tumors. Controls consisted of unrelated patients from the same clinic (119 men and 90 women, mean age $57 \pm 8.6$ ), who were hospitalized for various conditions but without any apparent cancer phenotype or history with ages corresponding to the age of the CRC patients $(\mathrm{p}<0.05)$. All samples were obtained from the Department of General and Colorectal Surgery, Medical University of Lodz. The study was approved by the Local Ethical Committee. The distribution of age, sex and stage of disease is listed in Table I.

\section{Genotyping}

DNA was isolated using QIAamp DNA Blood Mini Kit for isolation of high-molecular-weight DNA (Qiagen, Chatsworth, CA, USA). Genotypes were determined by RFLP-PCR (restriction fragment length polymorphism PCR) as described previously [16]. The volume of PCR reaction mixture was $10 \mu \mathrm{l}$ with the following content: 10 ng genomic DNA, PCR Master Mix (Fermentas, Vilnius, Lithuania) and $250 \mathrm{nM}$ of each primer (Sigma-Aldrich, St. Louis, MO, USA). Applied primers had the following sequence: sense,

5'-TTGGGGCCTCTTTGAGA-3' and antisense, 5'AACGGCTGAGGGTCTTCT-3'. PCR was performed in a T100 BIO-RAD thermal cycler (Herkules, CA, USA) under the following conditions: initial preheating step $95^{\circ} \mathrm{C}$ for 5 minutes, then 34 cycles of $95^{\circ} \mathrm{C}$ for 30 seconds, $57^{\circ} \mathrm{C}$ for 30 seconds, $72^{\circ} \mathrm{C}$ for 1 minute and a final extension step at $72^{\circ} \mathrm{C}$ for $7 \mathrm{~min}$ utes. The amplified $552 \mathrm{bp}$ product was digested with $2 \mathrm{U}$ of NlaIII restriction enzyme (NE Biolabs, New England, MA, USA) at $37^{\circ} \mathrm{C}$ overnight. Obtained fragments were separated on 3\% agarose gel for 1 hour at voltage of $110 \mathrm{~V}$. DNA was stained with ethidium bromide and visualized under UV light. There were three types of band pattern: $157 / 313 \mathrm{bp}, 105 / 208 / 239 / 313$ bp and 105/208/239 bp corresponding to the follow-

Table I. Distribution of age, sex and clinical characteristics in patient group

\begin{tabular}{|c|c|c|c|c|c|c|c|c|c|c|c|c|c|c|c|}
\hline \multirow{2}{*}{$\begin{array}{l}\text { Patients } \\
\text { No. }\end{array}$} & \multirow{2}{*}{$\begin{array}{c}\text { AGE } \\
\text { average }\end{array}$} & \multicolumn{2}{|c|}{ GENDER } & & \multicolumn{6}{|c|}{$\begin{array}{l}\text { CANCER STAGE ACCORDING } \\
\text { TO TNM CLASSIFICATION* }\end{array}$} & \multicolumn{5}{|c|}{$\begin{array}{l}\text { CANCER STAGE ACCORDING } \\
\text { TO AJCC CLASSIFICATION }\end{array}$} \\
\hline & & & & & & $\Gamma$ & & & $\mathrm{N}$ & & $\mathrm{M}$ & & I & II & III \\
\hline & & & & 1 & 2 & 3 & 4 & 0 & 1 & 2 & 0 & 1 & $(\mathrm{~T} 1-2 \mathrm{~N}$ & $3-4 \mathrm{~N}$ & $-4 N 1-2)$ \\
\hline 194 & $58 \pm 8.9$ & 83 & 111 & 4 & 45 & 139 & 6 & 114 & 55 & 25 & 191 & 3 & 36 & 78 & 80 \\
\hline
\end{tabular}


ing genotypes: Thr/Thr, Thr/Met, Met/Met. SNaPshot Multiplex System (Applied, Cleveland, OH, USA) was used to confirm concordance of genotypes in $10 \%$ samples. For polymorphic site recognition a primer was designed with the sequence as follows: 5'-ATCTGCAGTCCCTGGGGGCCA-3’. Genotyping was performed in accordance with the manufacturer.

\section{Statistical analysis}

Comparison of genotypes with Hardy-Weinberg expectations in both control and patient groups was verified by $X^{2}$ test. The evaluation of contribution of Thr241Met polymorphism to cancer development and progression was performed based on a multivariate regression model with $95 \%$ confidence interval (95\% CI).

\section{Results}

Distribution of Thr241Met polymorphism genotype in patients $\left(\mathrm{X}^{2}=1.817 ; \mathrm{p}=0.403\right)$ as well as in the control group $\left(\mathrm{X}^{2}=0.466 ; \mathrm{p}=0.792\right)$ corresponds with Hardy-Weinberg expectation. Heterozygous variant $\mathrm{Thr} / \mathrm{Met}$ is a distinctly more common genotype in the control (frequency: 0.5) than in the CRC group (frequency: 0.37). That disproportion is reflected in odd ratio values which indicate a statistically significant association of occurrence of heterozygotes $(\mathrm{OR}=$ $=0.57,95 \% \mathrm{CI}: 0.37-0.87)$ and the Met allele $(\mathrm{OR}=$ $=0.72$, 95\% CI: 0.54-0.97) with reduced CRC risk. There is no evidence for a risk modulation effect of remaining genotypes. The overall outcomes of genotyping are summarized in Table II.
Subsequently we performed an analysis of the influence of Thr241Met polymorphism on CRC progression. Based on the TNM cancer staging system, the AJCC malignant tumor classification was used to distinguish a group of patients in noninvasive first stage (I) and advanced second (II) and third stage (III) (Table I). Comparison of I separately to II and III showed no statistical significance as described in Table III. Additionally a $10 \%$ random selected sample from the control as well as the patient group was repeated. The outcome confirmed $100 \%$ compatibility.

\section{Discussion}

\section{Homologous recombination in CRC}

DSBs are widely considered to be among the greatest threat to genomic integrity. Colonic epithelial cells are constantly exposed to damage agents. Due to the capacity for penetrating tissues and material, ionizing radiation is a typical agent taken into account in relation to many cancers, including CRC. Nevertheless, there is some evidence supporting existence of an additional source of DSBs specific to CRC [17-19]. Approximately $80 \%$ of cases of sporadic CRC bear oncogenic chromosomal rearrangements that might have arisen as a consequence of defective DSBs. Therefore karyotypes of its cells are characterized by high aneuploidy and loss of heterozygosity. The formation of chromosomal aberrations is closely associated with mitotic events [20-22]. Homologous recombination as the main DSB repair pathway in S and early G2 phases of the cell cycle can play a pivotal role in carcinogenesis of sporadic CRC [6].

Table II. Genotype and allelic frequency distribution of XRCC3 Thr241Met gene polymorphisms and the risk of CRC

\begin{tabular}{|c|c|c|c|c|c|c|}
\hline \multirow[t]{2}{*}{ GENOTYPE/ALLELE } & \multicolumn{2}{|c|}{ Patients $(\mathrm{N}=194)$} & \multicolumn{2}{|c|}{ ConTROLS $(\mathrm{N}=209)$} & \multirow[t]{2}{*}{ OR $(95 \% \mathrm{CI})$} & \multirow[t]{2}{*}{$\mathbf{P}$} \\
\hline & NO. & FREQUENCY & NO. & FREQUENCY & & \\
\hline Thr/Thr & 97 & 0.5 & 80 & 0.38 & ref & - \\
\hline Thr/Met & 72 & 0.37 & 104 & 0.5 & $0.57(0.37-0.87) \downarrow$ & 0.01 \\
\hline Met/Met & 25 & 0.13 & 25 & 0.12 & $0.82(0.44-1.55)$ & 0.55 \\
\hline Thr & 266 & 0.61 & 264 & 0.63 & ref & - \\
\hline Met & 112 & 0.39 & 154 & 0.37 & $0.72(0.54-0.97) \downarrow$ & 0.03 \\
\hline
\end{tabular}

Table III. Effect of Thr241Met polymorphism on progression of colorectal cancer. Comparison of noninvasive stage I cases with stages II and III, based on the American Joint Committee on Cancer classification

\begin{tabular}{|c|c|c|c|c|c|c|c|c|c|c|}
\hline \multirow{2}{*}{$\begin{array}{l}\text { GENOTYPE/ } \\
\text { ALLELE }\end{array}$} & \multicolumn{2}{|c|}{ I (T1-2N0) } & \multicolumn{2}{|c|}{ II (T3-4N0) } & \multicolumn{2}{|c|}{ III (T1-4N1-2) } & \multicolumn{2}{|c|}{ II Vs. I } & \multicolumn{2}{|l|}{ III vs. I } \\
\hline & NO. & FREQUENCY & No. & FREQUENCY & NO. & FREQUENCY & OR $(95 \% \mathrm{CI})$ & $\mathrm{P}$ & OR $(95 \% \mathrm{CI})$ & $\mathbf{P}$ \\
\hline Thr/Thr & 20 & 0.56 & 36 & 0.46 & 41 & 0.51 & ref & - & ref & - \\
\hline Thr/Met & 13 & 0.36 & 33 & 0.42 & 26 & 0.33 & $1.41(0.61-3.28)$ & 0.42 & $0.98(0.41-2.29)$ & 0.56 \\
\hline Met/Met & 3 & 0.08 & 9 & 0.12 & 13 & 0.16 & $1.67(0.4-6.87)$ & 0.36 & $2.11(0.54-8.27)$ & 0.22 \\
\hline Thr & 53 & 0.74 & 105 & 0.67 & 108 & 0.68 & ref & - & ref & - \\
\hline Met & 19 & 0.26 & 51 & 0.33 & 52 & 0.33 & $1.36(0.73-2.52)$ & 0.34 & $1.34(0.72-2.5)$ & 0.35 \\
\hline
\end{tabular}




\section{Consequence of XRCC3 dysfunction}

The goal of this study was to evaluate the impact of XRCC3 Thr241Met polymorphism on CRC risk and progression. Due to premise for contribution of $X R C C 3$ in different stages of the HR pathway, the precise mechanism of its action remains still uncovered [79]. The vast majority of information on dysfunction of XRCC3 comes from studies on cell culture. Takata and colleagues observed reduction of sister chromatid exchange in chicken B-lymphocyte DT40 cells with deficiency of XRCC3 [23]. Furthermore, disturbances in formation of RAD51 foci in Chinese hamster ovary cell line irs $1 S F$ with lack of XRCC3 [8] and above-mentioned DT40 were noted [23]. Elevated frequency of chromosome segregation was observed in another investigation on irs $1 \mathrm{SF}$ carrying parallel deficiency of $X R C C 2$ and XRCC3 genes [24]. The other types of $X R C C 3(-/-)$ consequences might affect centrosome integrity [25]. Investigation performed on HTC116 colon cancer cell line with XRCC3(-/-) demonstrated similar manifestations as in the previously discussed experiment, such as reduction in sister chromatid exchange and impaired Rad51 focus formation. Additionally, genome duplication without mitosis (endoreduplication) under the condition of RPA overexpression [25] was noted. Variation in a single nucleotide cannot trigger such spectacular effects. However, the findings gathered above may indicate the direction of supposed disorders in the human organism.

\section{Studies on the Polish population}

In our investigation we screened genotypes of $194 \mathrm{pa}-$ tients with diagnosed CRC. As a control group there were recruited 209 cancer-free individuals, age- and sexmatched. We identified a significant statistical association between heterozygote Thr/Met and reduction of CRC risk. The same contribution was observed in relation to the Met allele. Simultaneously, the estimated OR in respect of progression risk was not significant (Table III). The number of studies concerning Thr241Met polymorphism in the Polish population with CRC is severely limited. There is one report which partially confirms our results in relation to $\mathrm{Thr} / \mathrm{Met}(\mathrm{OR}=0.26,95 \% \mathrm{CI}$ : 0.25 $0.27)$; nevertheless, the recessive variant $\mathrm{Met} / \mathrm{Met}$ (OR $=9.45,95 \%$ CI: 8.77-11.65) was identified as a factor elevating risk of CRC [26]. However, in a subsequent study the same authors observed a lack of Thr241Met polymorphism impact on CRC risk [27]. A similar conclusion follows from the Gil et al. investigation which found no statistical association in groups consisting of 133 CRC patients and 100 controls [28].

\section{Studies on other Caucasian populations}

Case-control studies carried out on other Caucasian populations such as Spanish, Norwegian and Czech also have not delivered evidence on participation of Thr241Met in development of CRC [29-31].

\section{Thr241Met polymorphism in various types of cancer}

By virtue of the non-specific character of DNA DSB as a carcinogenic agent in respect of one malignancy, XRCC3 remains a subject of research among many types of cancer. The majority of reports indicate an increased risk of cancer [32-34] as well as lack of effects [35-37]. In contrast, there are a few experimental studies pointing to the protective effect of XRCC3. Thirumaran $e t$ al. found an association among patients suffering from basal cell carcinoma of the skin, where $\mathrm{Thr} / \mathrm{Met}(\mathrm{OR}=0.71,95 \% \mathrm{CI}: 0.54-0.92)$ and Met/Met (OR $=0.54,95 \%$ CI: 0.36-0.80) were linked with decreased risk [38]. Diminishing risk in relation to a heterozygous variant $(\mathrm{OR}=0.3,95 \% \mathrm{CI}: 0.2-0.7)$ was also observed in a group of French individuals with supraglottic cancer [39]. Noteworthy is the Shen et al. report demonstrating lower risk for an additive model $(\mathrm{OR}=0.6,95 \% \mathrm{CI}: 0.4-0.91)$ in patients with bladder cancer. In addition, statistical significance was observed for appearance of the Met allele $(\mathrm{OR}=0.49$, 95\% CI: 0.28-0.88), but only within the subdivision of heavy smokers [40].

\section{Conclusions}

Although there is a lot of literature on XRCC3 Thr241Met polymorphism, the association with CRC remains hard to assess explicitly. Due to ambiguity of the results, the conclusion from our study ought to be considered with a high degree of caution. Nonetheless, there are some issues that support conclusions arising from our investigation. In the first instance, it needs to be emphasized that XRCC3 is commonly regarded as a gene of low penetrance. Moreover, its protein product is involved in different stages of $\mathrm{HR}$ that require cooperation with a large number of substrates. Thus, it allows us to surmise that the risk reduction effect can be a result of complicity of several single nucleotide polymorphisms located in different genes. Another unsettled issue is selection of the control group. To ensure the accurate capture of gene-environment interaction in sporadic cancer, we recruited persons without family history of cancer. However, in many studies discussed above, the criteria for control group inclusion do not contain that information. Thus, genetic burden unrelated to the subject might distort the results.

In conclusion, the outcome of our studies unambiguously suggests the decreased risk of CRC for Thr/Met genotype and the Met allele in Thr241Met $X R C C 3$ polymorphism. In order to explain how the genetic variation of homologous recombination genes con- 
tributes to sporadic CRC development, it is necessary to continue the case-control study on a broader spectrum of SNPs.

\section{The authors declare no conflict of interest.}

The study was supported by grant N N403 250340 from the Polish Ministry of Science.

\section{References}

1. Center MM, Jemal A, Ward E. International trends in colorectal cancer incidence rates. Cancer Epidemiol Biomarkers Prev 2009; 18: 1688-1694.

2. Ferlay J, Steliarova-Foucher E, Lortet-Tieulent J, et al. Cancer incidence and mortality patterns in Europe: Estimates for 40 countries in 2012. Eur J Cancer 2013; 49: 1374-1403.

3. Weitz J, Koch M, Debus J, et al. Colorectal cancer. Lancet 2005; 365: 153-165

4. Rich T, Allen RL, Wyllie AH, Defying death after DNA damage. Nature 2000; 407: 777-783.

5. Shrivastav M, De Haro LP, Nickoloff JA, Regulation of DNA double-strand break repair pathway choice. Cell Res 2008; 18 : 134-147.

6. Karanam K, Kafri R, Loewer A, et al. Quantitative Live Cell Imaging Reveals a Gradual Shift between DNA Repair Mechanisms and a Maximal Use of HR in Mid S Phase. Molecular Cell 2012; 47: 320-329.

7. He X-F, Su J, Zhang Y, et al. Need for clarification of data in the recent meta-analysis about RAD 51 135G $>$ C polymorphism and breast cancer risk. Breast Cancer Res Treat 2011; 129: 649651; author reply 52-53.

8. Bishop DK, Ear U, Bhattacharyya A, et al. Xrcc3 is required for assembly of Rad51 complexes in vivo. J Biol Chem 1998; 273: 21482-21488.

9. Forget AL, Bennett BT, Knight KL. Xrcc3 is recruited to DNA double strand breaks early and independent of Rad51. J Cell Biochem 2004; 93: 429-436.

10. Liu YL, Masson JY, Shah R, et al. RAD51C is required for Holliday junction processing in mammalian cells. Science 2004; 303 : 243-246.

11. Henry-Mowatt J, Jackson D, Masson JY, et al. XRCC3 and Rad51 modulate replication fork progression on damaged vertebrate chromosomes. Moll Cell 2003; 11: 1109-1117.

12. Barreiro LB, Laval G, Quach H, et al. Natural selection has driven population differentiation in modern humans. Nat Genet 2008; 40: 340-345.

13. He XF, Wei W, Li JL, et al. Association between the XRCC3 T241M polymorphism and risk of cancer: Evidence from 157 case-control studies. Gene 2013; 523: 10-19.

14. Zhan P, Wang Q, Qian Q, Yu LK. XRCC3 Thr241Met gene polymorphisms and lung cancer risk: a meta-analysis. J Exp Clin Cancer Res 2013; 32: 1

15. Wang Z, Zhang W. Association between XRCC3 Thr241Met polymorphism and colorectal cancer risk. Tumour Biol 2013; 34: 1421-1429.

16. David-Beabes GL, Lunn RM, London SJ. No association between the XPD (Lys751G1n) polymorphism or the XRCC3 (Thr241Met) polymorphism and lung cancer risk. Cancer Epidemiol Biomarkers Prev 2001; 10: 911-912.

17. Toden S, Bird AR, Topping DL, Conlon MA. High red meat diets induce greater numbers of colonic DNA double-strand breaks than white meat in rats: attenuation by high-amylose maize starch. Carcinogenesis 2007; 28: 2355-2362.

18. Nougayrède JP, Homburg S, Taieb F, et al. Escherichia coli induces DNA double-strand breaks in eukaryotic cells. Science 2006; 313: 848-851.
19. Cuevas-Ramos G, Petit CR, Marcq I, et al. Escherichia coli induces DNA damage in vivo and triggers genomic instability in mammalian cells. Proc Natl Acad Sci U S A 2010; 107: $11537-$ 11542.

20. Dalton WB, Yang VW. Mitotic Origins of Chromosomal Instability in Colorectal Cancer. Curr Colorectal Cancer Rep 2007; 3: 59-64.

21. Kops GJ, Weaver BA, Cleveland DW. On the road to cancer: aneuploidy and the mitotic checkpoint. Nat Rev Cancer 2005; 5: 773-785.

22. Cleary ML. Oncogenic conversion of transcription factors by chromosomal translocations. Cell 1991; 66: 619-622.

23. Takata M, Sasaki MS, Tachiiri S, et al. Chromosome instability and defective recombinational repair in knockout mutants of the five Rad51 paralogs. Moll Cell Biol 2001; 21: 2858-2866.

24. Griffin CS, Simpson PJ, Wilson CR, et al. Mammalian recombination-repair genes XRCC2 and XRCC3 promote correct chromosome segregation. Nat Cell Biol 2000; 2: 757-761.

25. Daboussi F, Thacker J, Lopez BS. Genetic interactions between RAD5 1 and its paralogues for centrosome fragmentation and ploidy control, independently of the sensitivity to genotoxic stresses. Oncogene 2005; 24: 3691-3696.

26. Krupa R, Blasiak J. An association of polymorphism of DNA repair genes XRCC1 and XRCC3 with colorectal cancer. J Exp Clin Cancer Res 2004; 23: 285-294.

27. Krupa R, Sliwinski T, Wisniewska-Jarosinska M, et al. Polymorphisms in RAD51, XRCC2 and XRCC3 genes of the homologous recombination repair in colorectal cancer - a case control study. Mol Biol Rep 2011; 38: 2849-2854.

28. Gil J, Ramsey D, Stembalska A, et al. The C/A polymorphism in intron 11 of the XPC gene plays a crucial role in the modulation of an individual's susceptibility to sporadic colorectal cancer. Mol Biol Rep 2012; 39: 527-534.

29. Skjelbred CF, Saeb? M, Wallin H, et al. Polymorphisms of the XRCC1, XRCC3 and XPD genes and risk of colorectal adenoma and carcinoma, in a Norwegian cohort: a case control study. BMC Cancer 2006; 6: 67.

30. Moreno V, Gemignani F, Landi S, et al. Polymorphisms in genes of nucleotide and base excision repair: risk and prognosis of colorectal cancer. Clin Cancer Res 2006; 12 (7 Pt 1): 2101-2108.

31. Pardini B, Naccarati A, Novotny J, et al. DNA repair genetic polymorphisms and risk of colorectal cancer in the Czech Republic. Mutat Res 2008; 638: 146-153.

32. Costa S, Pinto D, Pereira D, et al. DNA repair polymorphisms might contribute differentially on familial and sporadic breast cancer susceptibility: a study on a Portuguese population. Breast Cancer Res Treat 2007; 103: 209-217.

33. Popanda O, Schattenberg T, Phong CT, et al. Specific combinations of DNA repair gene variants and increased risk for nonsmall cell lung cancer. Carcinogenesis 2004; 25: 2433-2441.

34. Winsey SL, Haldar NA, Marsh HP, et al. A variant within the DNA repair gene XRCC3 is associated with the development of melanoma skin cancer. Cancer Res 2000; 60: 5612-5616.

35. Loizidou MA, Michael T, Neuhausen SL, et al. Genetic polymorphisms in the DNA repair genes XRCC1, XRCC2 and XRCC 3 and risk of breast cancer in Cyprus. Breast Cancer Res Treat 2008; 112: 575-579.

36. Misra RR, Ratnasinghe D, Tangrea JA, et al. Polymorphisms in the DNA repair genes XPD, XRCC1, XRCC3, and APE/ref-1, and the risk of lung cancer among male smokers in Finland. Cancer Lett 2003; 191: 171-178.

37. Sanyal S, Festa F, Sakano S, et al. Polymorphisms in DNA repair and metabolic genes in bladder cancer. Carcinogenesis 2004; 25: 729-734.

38. Thirumaran RK, Bermejo JL, Rudnai P, et al. Single nucleotide polymorphisms in DNA repair genes and basal cell carcinoma of skin. Carcinogenesis 2006; 27: 1676-1681. 
39. Benhamou S, Tuimala J, Bouchardy C, et al. DNA repair gene XRCC2 and XRCC3 polymorphisms and susceptibility to cancers of the upper aerodigestive tract. Int J Cancer 2004; 112: 901-904.

40. Shen M, Hung RJ, Brennan P, et al. Polymorphisms of the DNA repair genes XRCC1, XRCC3, XPD, interaction with environmental exposures, and bladder cancer risk in a case-control study in northern Italy. Cancer Epidemiol Biomarkers Prev 2003; 12 (11 Pt 1): 1234-1240.

\section{Address for correspondence}

Ireneusz Majsterek $\mathrm{PhD}$

Department of Clinical Chemistry and Biochemistry

Medical University of Lodz

e-mail: ireneusz.majsterek@umed.lodz.pl 